\title{
MODIFICACIONES DEL PAISAJE DURANTE EL PLEISTOCENO SUPERIOR-HOLOCENO EN LOS TERRITORIOS LITORALES ATLÁNTICOS DEL NW IBÉRICO
}

\author{
Gómez-Orellana R., L.; Ramil-Rego, P. \& Martínez Sánchez, S.*
}

Resumo

\begin{abstract}
Modificaçōes da paisagem durante o Plistocénico Superior-Holocénico nos territórios litorâneos atlânticos do NW ibérico-A informação paleobotânica e cronológica obtida em diversos depósitos limnéticos de natureza poligênica situados na actual área litoral Atlântica ( $N$ de Portugal e $\mathrm{S}$ da Galiza) permite avaliar as mudanças da paisagem vegetal desse território, correlacionando-as com a dinâmica climática global estabelecida para o Sudoeste da Europa. O início da seqüência situar-se-ia no âmbito do Interestagial Würmiano (Estágio Isotópico 3), durante o qual se constata a presença, na área litoral, de formações arbóreas. A posterior deterioração climática representada pelo Estágio Würmiano Final aparece refletida no desenvolvimento de formações arbustivas, cujo predominio se estende até o início do actual interglacial. A dinâmica aqui obtida é compativel cronológica e ecologicamente com as seqüências regionais obtidas em outras áreas do Noroeste ibérico. A transgressão Flandriana provocou grandes modificações no espaço litoral do Noroeste Ibérico. Como conseqüência, os depósitos limnéticos formados no final do Pleistocénico e/ou no inicio do Holocénico, en áreas distantes da costa, ficaram siluados próximos a esta ou submergidos no prelitoral. Esses processos virão ligados, em muitos casos, ao recobrimento dos sedimentos por materiais detríticos de natureza continental e/ou marinha, o que provoca a cobertura da maioria dos depósitos mais antigos. As mudanças geomorfológicas repercutem na representatjvidade polinica dos sedimentos recuperados nesses depósitos, de modo que a partir de meados do Holocénico aprecia-se uma óptima representatividade da dinâmica das comunidades litorâneas (vegetaçẫo halófila, matorrais, úmidas), enquanto que as comunidades de carácter climatófilo, próprias de meios continentais, mantêm um minimo reflexo, em consonância com a sua escassa significação na paisagem.
\end{abstract}

Palabras-chave: Análise polínico, Plistocénico Superior, Holocénico, Litoral, NW Ibérico

Abstract

\begin{abstract}
Landscape modifications during the Upper Pleistocene-Holocene in the NW Atlantic margin of Iberian Peninsula - The palaeobotanical, climatic reflection and chronological information obtained in the different limnic deposits of different sources in the actual Atlantic margin between $N$ Portugal and $S$ Galicia, allow us to ascertain the plant landscape changes of this coastal region and to evaluate the existing land/sea correlation with the global climatic events that happenned at that time in SW Europe. The beginning of the sequence corresponds to the Würm Interstadial (Isotopic Stadial 3) during which there was a development of tree formations in the coastal area. The further deterioration of the weather quality is represented by the establishment of shrub formations in the Wurm Final Stadial, this dynamic tasts until early actual interglacial age and corresponds chronologically and ecologically with other regional sequences in other areas of NW Iberia. The Flandrian trasgression caused big modifications in the constal area of NW Iberian Peninsula; as a consequence the limnic deposiss, formed during LatePleistocene and/or at Early-Holocene in inner areas far away from the coast, were progressively approach to adjacent outer lands and finally arrived close to the coast or in such an extent submerged in the vecinity of the offshore NW Spain. These events were associated in many cases with a sediment entrapment by detritic particle input and the resulting sedimentary deposits of continental and/or marine nature, this mechanism would promote the sealing of almost all the ancient deposits. The geomorphological changes affect the pollen representation in the sampled sediments for these deposits, in such a way that at Middle-Holocene is seen a good representation of the dynamics of the coastal vegetation communities (halophyllous plants, shrublands, wetlands), whereas the dominant climatic communities -typical of continental lands- shown a minimal representation in that habitat which in turns is in accordance with their poor importance in the landscape.
\end{abstract}

Key-words: Pollen analysis, Upper Pleistocene, Holocene, Atlantic margin, Iberian Peninsula

\section{INTRODUCCIÓN}

La actual situación de conocimiento paleoecológico de los periodos Tardiglaciar y Holoceno en el NW de la Península Ibérica permite establecer correctamente la dinámica de la vegetación para estos periodos, estado que no puede ampliarse para periodos anteriores al
18.000 o incluso al 15.000 BP. En gran parte de los territorios interiores y montañosos el predominio de los fenómenos de resistasia durante el máximo glaciar Würmiense ha causado el rejuvenecimiento o la denudación de los depósitos limnéticos, dificultando la presencia de registros polínicos u otros paleoindicadores de las condiciones climáticas imperantes. 
La mayoría de los datos paleobotánicos disponibles para el Pleistoceno Final en la Península Ibérica, se refieren al estudio de sedimentos emplazados en áreas mediterráneas: Turbera de Padul (Pons \& Reille, 1988) Pla de l'Estany (Burjachs I Casas, 1990), u obtenidos a partir de formaciones kársticas y abrigos rocosos de la Cornisa Cantábrica, cuya idoneidad a la hora de establecer la dinámica paleoambiental de un territorio ha sido puesta de manifiesto en numerosas ocasiones (TURNER \& HANNON, 1988; SÁnchez GoÑl, 1991; Ramil-Rego, 1992; RamiLREGo et al., 1996A, etc.). Pese a la significación regional de los datos aportados en las secuencias de la Iberia mediterránea, las reconstrucciones climáticas globales reflejan marcadas diferencias en cuanto a temperatura y humedad durante los diferentes episodios Würmienses entre estos territorios y el NW de la Península Ibérica (Frenzel, 1968, 1989; Frenzel ET AL., 1992, etc.).

Frente a la inestabilidad geomorfológica evidenciada en los territorios interiores del NW penínsular, en el espacio litoral Atlántico del NW de la Península Ibérica, se constata la presencia de un amplio elenco de sedimentos limnéticos fosilizados, cuya formación se sitúa en el ámbito del último ciclo Glaciar/ Interglaciar del Pleistoceno, concentrando la practica totalidad de los registros polínicos del territorio para periodos anteriores al 20.000 BP (RAMLL-REGO ET AL., 1996; RAMIL-REGO \& GÓMEZ-ORELLANA, 1996).

Estos ciclos orgánicos, aparecen intercalados entre sedimentos de diferente naturaleza y en columnas de mayor o menor complejidad según los casos, presentándose en la mayoria de las ocasiones sepultados y fosilizados por la posterior deposición de materiales de naturaleza inorgánica, debido a la acción de los agentes geodinámicos externos y en respuesta a cambios ambientales desarrollados a nivel global. En general, el estudio paleobotánico de estos niveles, muestra el dominio local de macrófitos acuáticos e higrófitos de marcado carácter continental y rigurosamente halófobo; carácter que coincide con el dado por otros autores, basándose en análisis sedimentológicos

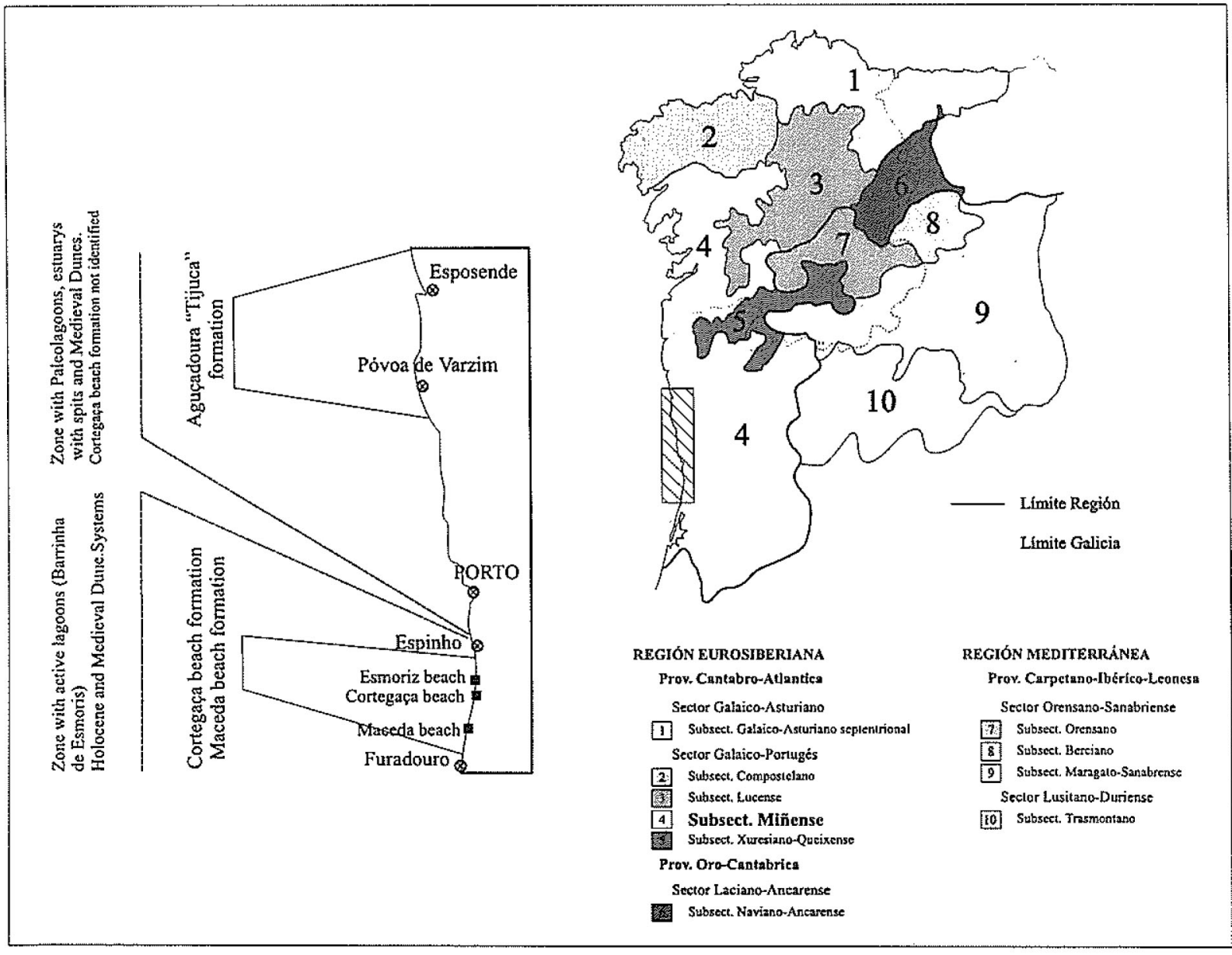

Fig. I-Mapa corológico del NW de la Península lbérica (Modificado a partir de lzCo \& SANCHEZ, 1995) y área de estudio
Fig. 1-Corologic map of the West end of Iberian Peninsula (Redraw from Izco \& Sinciez, 1995), and study area. 
(NONN, 1966; BUTZER, 1967; MARY et al., 1977; Brosche, 1982, 1983; MARY, 1983; MATEUS, 1992; Granja \& Carvalho, 1993; Meireles \& Texier, 1993; GRANJA et al., 1995; etc.). Este carácter mayoritariamente continental de los niveles limnéticos, que conforman estos depósitos, emplaza su formación en un momento de transgresión oceánica anterior a la transgresión Flandriense $(6.000 \mathrm{BP})$, que en la mayoría de los casos será la causa de su desmantelamiento vertical.

En este trabajo se presentan un conjunto de análisis polínicos realizados en formaciones sedimentarias del litoral Norte de Portugal, que a su vez se integran a resultados previos obtenidos en los territorios atlánticos emplazados al $\mathrm{N}$ del río Minho, para establecer las modificaciones del paisaje y la vegetación en los territorios litorales de la ecoregión Atlántica (Eurosiberiana) de la Península Ibérica, desde el Würm medio hasta la actualidad, encuadrándola en el marco de la evolución global establecida para el SW de Europa.

\section{2. Área de estudio}

El espacio litoral se entiende desde el punto de vista ecológico, como un espacio dinámico en constante evolución a través del tiempo, siendo causas principales de este dinamismo, los movimientos epirogénicos y las oscilaciones eustáticas, cuya incidencia hace mermar o incrementar la superficie de este particular espacio.

Dentro del espacio litoral se incluyen aquellos territorios sobre los que el Océano extiende su influencia climática, entendiendo esta como la presencia de una elevada pluviosidad y grado de humedad ambiental, así como el efecto amortiguador que la presencia del mar ejerce sobre la temperatura (Fig. 3).

\section{Material y Metodos}

El muestreo y la extracción del residuo esporopolínico se realizó siguiendo los métodos habituales en palinología (Moore et al., 1991). Para la representación de los resultados, se han calculado los valores porcentuales de cada taxón con respecto a la suma polínica total.. Para cada taxón se han representado dos curvas: la primera (sólida) muestra las frecuencias polínicas reales, y la segunda (trama) los valores multiplicados por diez (Fig. 5, 6, 7 y 8).

En los tres depósitos analizados, el muestreo se realizó de forma manual. De los siete niveles recogidos tres fueron considerados polínicamente estériles tras la realización de dos extracciones consecutivas. El residuo extraído a partir de estos últimos, presenta una gran cantidad de hifas fúngicas y una exigua cantidad de polen.

\section{Depósitos}

\subsection{Litoral Atlántico de Galicia}

Desde que en la década de los cuarenta, se publican los primeros trabajos en que se hace referencia a la existencia de depósitos limnéticos fosilizados en el litoral Atlántico de Galicia (ZBYZEWSKI \& TEIXEIRA 1949; ZBYZEWSKI 1958; etc.), han salido a la luz gran número de trabajos que en su mayoría hacen referencia a aspectos geomorfológicos, sedimentológicos o paleobotánicos (NONN, 1966; SAÁ, 1975; CANO, et al., 1997. RAMIL-Rego \& GómEz-OrElLANA 1996; Gómez-Orellana, 1997; Gómez-Orellana et al., 1998 etc.).

Recientemente se ha publicado un estudio que engloba desde una óptica integradora, la caracterización y análisis polínico de los depósitos fosilizados situados en el área litoral de Galicia, obteniéndose una secuencia paleoclimática para este territorio que abarca la totalidad del último ciclo GlaciarInterglaciar del Cuaternario (RAMIL-REgo \& GÓMEZOrellana, 1996; Gómez-Orellana, 1997; GómezOrELlanA et al., 1998).

Los datos aportados en esta serie de trabajos han permitido elaborar una caracterización sintética de los depósitos presenten los territorios litorales de Galicia, así como una propuesta cronológica que se muestra de forma resumida en la figura 2. En la misma, se puede apreciar como los niveles inorgánicos están constituidos por materiales aluviales, coluviales o periglaciares, restringiéndose las facies de origen marino (restos fosilizados de dunas de arenas y playas de cantos) a los periodos integlaciares (Eemiense y Holoceno).

\subsection{Sur de la desembocadura del río Miño}

En las áreas más próximas a la desembocadura del río Miño, los depósitos presentan bastantes analogías con los situados al $\mathrm{N}$ de esta desembocadura (TeIXer \& Meireles, 1987; Teixer et al., 1989, etc). Estas caracteristicas contrastan sin embargo, con las descripciones disponibles para los depósitos emplazados más al $\mathrm{S}$, entre los cuales dominan las facies de playa y/o duna, frente a los niveles coluvio/aluviales $o$ periglaciares.

En los últimos años, este litoral ha sido objeto de un intenso estudio, en el que se incluyen análisis geológicos, sedimentológicos, estratigráficos, cronológi$\cos$, micropaleontológicos, antracológicos, etc., pero entre los cuales no se había incluido el análisis paleobotánico de los niveles limnéticos presentes en estas 
formaciones (CARVALHO \& GRANJA, 1991; GRANJA \& Carvalho, 1993; Granja \& De Groot, 1996, etc.). Estos estudios han revelado la existencia de forma más o menos continua, durante el Pleistoceno FinalHoloceno de un complejo sistema lagunar ocupando amplias áreas de la zona litoral del Norte de Portugal. Dicho sistema ha ido evolucionando durante estos periodos en relación con la posición ocupada por la línea de costa, pasando por fases de anegación-colmatación hasta desembocar en la actual situación, provocada tras la trasgresión Flandriense, en la que de este sistema únicamente permanecen de forma residual las lagunas de Mira, Esmoriz o la de Apúlia.
La información paleobotánica disponible para los territorios del $\mathrm{N}$ de Portugal, se refiere a diversos depósitos emplazados en las depresiones y sierras sublitorales en la región del Minho cuyo registro cronológico no supera los $3.000 \mathrm{BP}$ (Tabla 1) o a registros de mayor cobertura cronológica, obtenidos en la Serra do Xurês (Ramll-Rego ET AL., 1996B). Por contra, los territorios litorales para los que se dispone de mayor cantidad de información, son los emplazados en el área mediterránea en los cuales se han obtenido varias secuencias cuyo registro abarca principalmente el actual interglaciar (ELHAl, 1964; QUEIROZ, 1985, 1989; MATEuS, 1992, etc.). Los datos obtenidos para

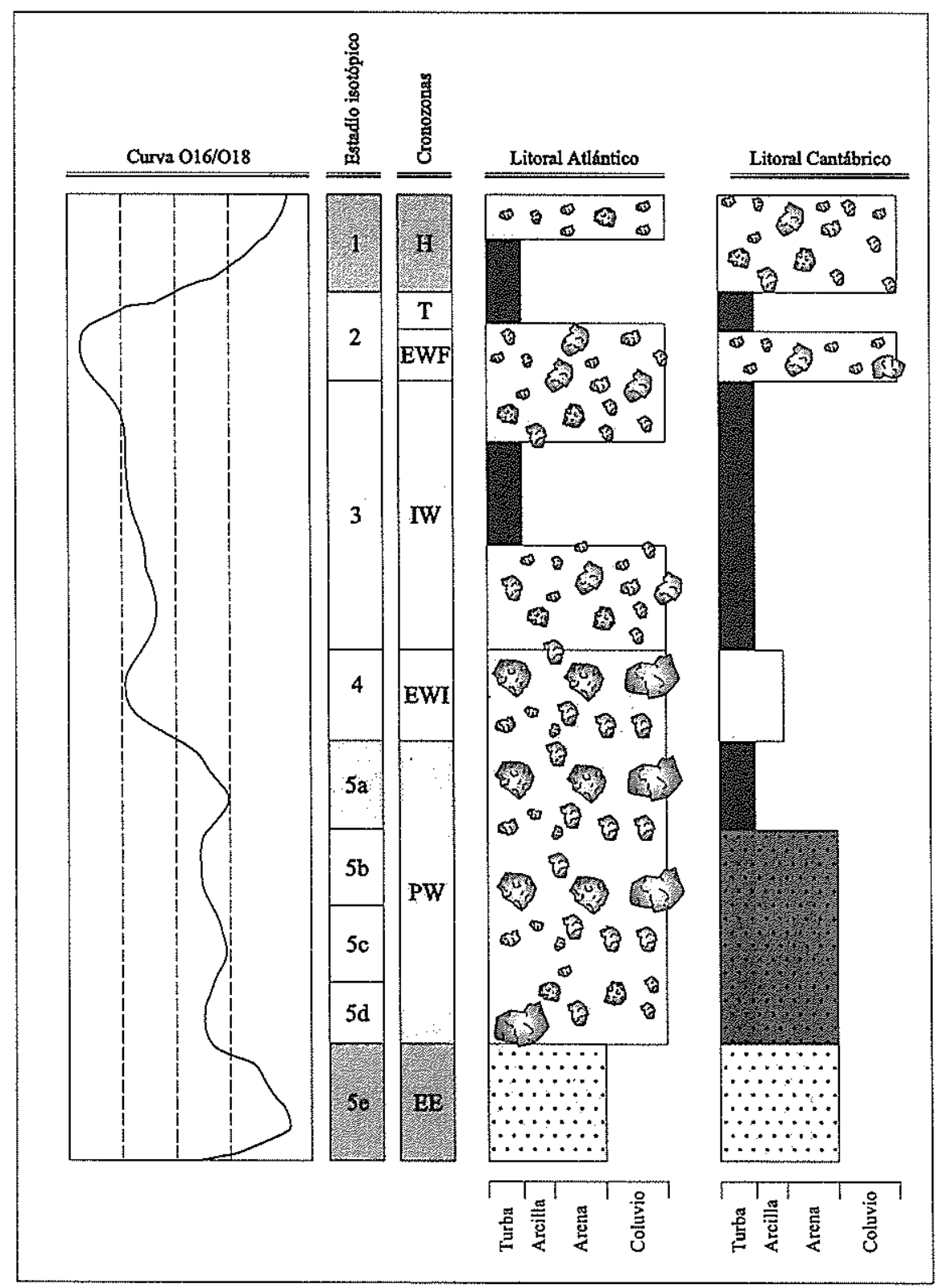

Fig. 2-Secciones idealizadas de los depósitos litorales de Galicia.

Fig. 2-Ideal sections of the litoral deposits of Galicia. 
periodos anteriores al 15.000 BP (ANDRADE 1944, 1945 , etc.), se refieren mayoritariamente a estudios realizados en formaciones emplazadas en el área mediterránea (área costera al Sur de Lisboa y Estremadura Portuguesa), cuya atribución cronológica presenta grandes controversias (Mateus \& Queiroz, 1993); al tiempo, gran parte de los análisis paleobotánicos disponibles, dejan como resultado una información paleobotánica aquejada de graves deficiencias metodológicas y de escaso valor a la hora de realizar una reconstrucción paleoambiental (MATEUS \& QUEIROZ, 1993).

\begin{tabular}{|l|l|l|}
\hline \multicolumn{1}{|c|}{ Denominación } & Cronología & \multicolumn{1}{|c|}{ Bibliografia } \\
\hline Chão da Cheira I & $<3.000 \mathrm{BP}$ & Ramil-Rego et al, 1996b \\
Chão da Cheira II & $<3.000 \mathrm{BP}$ & Ramil-Rego et al, 1996b \\
Monte Borrelho 1 & $<3.000 \mathrm{BP}$ & Ramil-Rego et al, 1996b \\
Monte Borrelho II & $<3.000 \mathrm{BP}$ & Ramil-Rego et al, 1996b \\
Castro S. João d Rei & $<3.000 \mathrm{BP}$ & Ramil-Rego et al, 1996b \\
Castro S Juliaõ I & $<3.000 \mathrm{BP}$ & Aira \& Ramil, 1993 \\
Castro S Juliaõ II & $<3.000 \mathrm{BP}$ & Aira \& Ramil, 1993 \\
Castro S Juliaõ III & $<3.000 \mathrm{BP}$ & Aira \& Ramil, 1993 \\
Castro de Sola I & $<3.000 \mathrm{BP}$ & Aira \& Ramil, 1993 \\
Castro de Sola II & $<3.000 \mathrm{BP}$ & Inédito \\
\hline
\end{tabular}

Tabla 1-Análisis polínicos realizados en las depresiones y sierras sublitorales de la región de Minho.

Table 1-Main pollen secuences of the Interior Depresions and Sub-coastal mountains of Minho región.

Los análisis polínicos realizados en este tramo litoral y que se presentan en este trabajo, se refieren a niveles limnéticos emplazados entre facies de duna, playa o intermareales, ubicados entre las localidades de Ovar y Espinho, concretamente los depósitos de Maceda, Esmoriz y Aguçadora, cuya descripción sedimentológica y cronología, pormenorizada en numerosos trabajos, se describe en las tablas $2,3,4$ y 5 .

\section{Resultados}

\subsection{Depósito de Aguçadoura}

El depósito de Aguçadoura, se incluye, dentro de la formación sedimentaria de igual nombre, que se desarrolla a lo largo del área litoral comprendida entre la localidad de Esposende y la desembocadura del río Ave. A partir del análisis de los diferentes afloramientos y de los resultados de una serie de sondeos, Granja y Soares de Carvalho (Granja 1991; GRANJA \& CARVALHO, 1993, etc.) realizan una descriptiva de este depósito, que se muestra de forma resumida en la tabla 2.

La unidad analizada, se corresponde con un nivel de arenas finas, oscuras y limosas con turbas y diatomeas, denominada localmente como «Tijuca». En diferentes áreas de afloramiento de esta formación, se han obtenido varias dataciones radiocarbónicas (Tabla 2), tanto a partir del propio material como de macrorrestos vegetales incluidos en el mismo. Las fechas sitúan su formación, entre 4.470 BP y 360 BP (CARVALHO \& Granja, 1991; Granja \& CarValHo, 1993; Granja \& CarvalHo, 1994 etc.).

FORMACION DE «TIJUCA» DE AGUÇADOURA

\begin{tabular}{|l|l|}
\hline \multicolumn{1}{|c|}{ Unidades estratigráficas } & \multicolumn{1}{|c|}{ Cronologia (años BP) } \\
\hline Arenas de duna & \\
Arenas intermareales & \\
Arenas finas, oscuras y limosas & Cortes: $920 \pm 80$ to3.250 \\
con turbas y diatomeas & Sondeos: $360 \pm 40$ to $4.470 \pm 50$ \\
(«Tijuca) & \\
Arenas fluviales & \\
Cantos marinos & \\
\hline
\end{tabular}

Tabla 2 - Unidades estratigráficas y dataciones radiocarbónicas de la formación de «Tijuca» de Aguçadoura . (A partir de Granja \& Soares, 1993).

Table 2-Stratigraphic units and radiocarbon dates of the Cortegaça Beach formation. From Granja \& Soares, 1993.

En un afloramiento situado en las proximidades de la localidad de Póvoa do Varzim, se muestreó para su análisis palinológico, un nivel de $30 \mathrm{~cm}$. de potencia, correspondiente a la citada unidad. El diagrama obtenido a partir del análisis polínico realizado (Fig 4), muestra un absoluto predominio del polen no arbóreo, entre el cual destacan por sus porcentajes: Tubuliflorae $(45 \%)$, Poaceae $(30 \%)$ o Artemisia $(20 \%)$. Entre el polen arbóreo están presentes, Quercus robur tp, Quercus ilex tp, Corylus, Betula o Ulmus (Fig 4).

Los datos permiten considerar la existencia de un paisaje fuertemente deforestado, en consonancia con el periodo temporal que refleja la secuencia. La elevada representación que muestran táxones como Artemisia o Tubuliflorae, generalmente relacionados con la presencia de un clima frío y seco, deben interpretarse sin embargo como elementos pertenecientes a comunidades halófilas de carácter azonal.

La representación de la vegetación acuática esta dominada por Isoetes, que alcanza un máximo del $80 \%$; además están presentes una gran variedad de táxones higrófilos entre los que destacan Cyperaceae y Umbelliferae.

\subsection{Depósito de Cortegaça}

Los depósitos situados en el cantil de la playas de Esmoriz y Cortegaça, han sido descritos y englobados en una formación sedimentaria denominada de Cortegaça. Dicha formación comprende, siguiendo la descriptiva propuesta en los trabajos de Granja y Soares de Carvalho (Granja, 1991; Granja \& CARvalho, 1993; Granja \& De Groot, 1996, etc.) de 
base a techo una serie facies sedimentarias que sintéticamente se reflejan en la tabla 3 .

En este depósito se recogieron para su análisis, muestras de tres niveles, dos de los cuales se corresponden con el horizonte Al del podzol (nivel P) y con el nivel lagunar (nivel V) situado en la parte basal del perfil; el tercero (Cortegaça 2) se recogió en un pequeña playa situada en el acceso Norte de la playa de Esmoriz y que probablemente se corresponda con el nivel $\mathrm{V}$.

\section{FormaCión de la Playa dE CORTEGAÇA}

\begin{tabular}{|l|l|}
\hline \multicolumn{1}{|c|}{ Unidades estratigráficas } & Cronologia (años BP) \\
\hline Arenas eólicas & \\
Nivel intermareal & \\
Podzol & \\
Horizonte A1 (Cortegaça P) & $950 \pm 80$ to $3.490 \pm 60$ \\
Horizonte A2 & \\
Nivel intermareal & \\
Nivel lacunar (Cortegaça V) & $5.500 \pm 160$ and $6.850 \pm 60$ \\
Arenas claras & \\
\hline
\end{tabular}

Tabla 3 - Unidades estratigráficas y dataciones radiocarbónicas de la formación de la playa de Cortegaça. (A partir de Granja \& Soares, 1993).

Table 3 - Stratigraphic units and radiocarbon dates of the Cortegaça Beach formation. From Granja \& Soares, 1993.

De los tres niveles analizados en este depósito (Tabla 3) únicamente en dos se han obtenido los valores polínicos necesarios para la realización de una interpretación paleoambiental; el tercero de los niveles (Cortegaça P), se consideró estéril polinícamente. Los datos obtenidos en los niveles Cortegaça $\mathrm{V}$ y Cortegaça 2 se muestran en las figuras $5 a$ y $5 b$.

El nivel Cortegaça 2, se caracteriza por el dominio del polen herbáceo, principalmente de Poaceae, que llega a alcanzar valores del $60 \%$ o Tubuliflorare con porcentajes en torno al $25 \%$, mientras la representación del total de polen arbóreo se mantiene en valores inferiores al $15 \%$. Hacia el final de la secuencia descienden los porcentajes de Poaceae, observándose un incremento de los valores de Calluna, Artemisia y Juniperus en primer lugar y finalmente del polen arbóreo, con las expansiones de Pinus (cf. Pinea).

En cuanto a la representación de los táxones estrictamente locales se observa el absoluto predominio de Isoetes con máximos del $40 \%$, que hacia el final de la secuencia descienden paulatinamente mientras se incrementan los valores de Ranunculus (Fig. 5a).

Por el contrario, el diagrama obtenido en el nivel Cortegaça V (Fig. 5b), refleja inicialmente el predominio de los tipos polínicos arbóreos, principalmente Pinus pinaster y Pinus cf. pinea, siendo muy escasa la representación de los taxones caducifolios. Posteriormente se produce una sustitución de Pinus pinaster y Pinus cf. pinea por Calluna, y finalmente descienden los porcentajes de estos tres táxones incrementandose los de Juniperus, Poaceae y Cruciferae. La vegetación acuatica evidencian de nuevo el predominio de Isoetes, y finalmente un acusado descenso de sus porcentajes coincidiendo con los incremento de Poaceae, Cruciferae y Juniperns.

\subsection{Depósito de S. Pedro de Maceda}

El depósito se localiza en la playa de San Pedro de Maceda, en las proximidades de la localidad de Espinho y se incluye en la formación denominada de Maceda (Granja \& Carvalho 1993; De Groot \& GRANJA, 1998, etc.). Esta formación sedimentaría esta formada por una alternancia de ambientes lacunares y de playa. A partir de carbones recogidos en el seno de los tres niveles lacunares reconocidos se han obtenido dataciones radiocarbónicas (Tabla 4) que permiten atribuir su formación al Estadial Würmiense Final (25.000-15.000 BP).

\section{Formación de la Playa de Maceda}

\begin{tabular}{|l|c|}
\hline \multicolumn{1}{|c|}{ Niveles lacunares } & Cronologia (años BP) \\
\hline Niveles superiores & $14.300 \pm 160$ \\
Niveles intermedios & $23.625 \pm 570$ \\
Niveles inferiores & $24.625 \pm 590$ \\
& $26.700 \pm 1000$ \\
\hline
\end{tabular}

Tabla 4 - Unidades estratigráficas y dataciones radiocarbónicas de la formación de la playa de Maceda. (A partir de Granja \& Soares, 1993).

Table 4-Stratigraplic units and radiocarbon dates of the Maceda Beach formation. (From Granja \& Soares, 1993).

Además, se incluyen dentro de esta formación una gran cantidad de macrorrestos leñosos no carbonizados, correspondientes mayoritariamente a ramas y troncos de Pinus, emplazados bajo el actual nivel del mar en las localidades de San Pedro de Maceda y Esmoriz.

La abundancia y disposición espacial de los macrorrestos permite considerar la existencia de un antiguo bosque de coníferas que posteriormente fue sepultado por un nivel de playa, a techo del cual se sitúan las distintas facies descritas en esta formación (Tabla 4). Las dataciones obtenidas en varios troncos sitúa la formación del bosque hacia el final del Interestadial Würmiense y el comienzo del Estadial Würmiense Final (Tabla 5).

La deposición masiva de arena eólica y mareal, favoreció la conservación de los macrorrestos al establecerse un medio aerobio, donde la actividad descomponedora microbiana se vio dificultada. 
Formación de la Playa de MACEDA

\begin{tabular}{|l|l|}
\hline \multicolumn{1}{|c|}{ Troncos y ramas } & \multicolumn{1}{c|}{ Cronología (años BP) } \\
\hline Rama & $20.600 \pm 300$ \\
Rama & $22.600 \pm 550$ \\
Rama & $24.500 \pm 260$ \\
Tronco & $25.300 \pm 160$ \\
Tronco & $25.390 \pm 440$ \\
Tronco & $28.000 \pm 100$ \\
Tronco & $25.400 \pm 240$ \\
Rama & $29.100 \pm 510$ \\
Tronco & $29.000 \pm 690$ \\
\hline
\end{tabular}

Tabla 5-Dataciones radiocarbónicas obtenidas a partir de troncos y ramas en la formación de la playa de Maceda. (A partir de Granja \& Carvalho, 1995).

Table 5-Radiocarbon dates obtained on Trunks and Branchs of Maceda beach formatión. (From Granja \& Carvalho, 1995).

En este depósito se realizó un muestreo en tres niveles lacunares, dos situados en la parte central de la playa (Maceda $\mathrm{A}$ y Maceda $\mathrm{D}$ ) y un tercero más hacia el Norte, y que se ha denominado Maceda II

Únicamente uno de los tres niveles, la cantidad de polen obtenida ha permitido la realización de un diagrama de porcentajes (Maceda II); los dos niveles restantes han sido considerados polínicamente estériles tras examinar el resultado de dos extracciones consecutivas.

A lo largo del diagrama obtenido en el nivel II de Maceda (Fig. 6) se observa una clara hegemonía del polen arbustivo, principalmente de Jiniperus, que alcanza porcentajes cercanos al $40 \%$, juntamente con un amplio elenco de táxones arbustivos, como Calluna, Erica, Ulex tp. Myrica o Daphne, con porcentajes siempre inferiores al $5 \%$. Mientras, entre los taxones herbáceos el predominio corresponde a Poaceae y en menor medida a Tubuliflorae, observándose hacia el final de la secuencia un ligero incremento de Artemisia, (Fig. 6).

Entre el escaso polen arbóreo registrado destacan Pinus sylvestris y Quercus robur tp., con curvas continuas y porcentajes inferiores al $5 \%$; además estan presentes otros táxones como Quercus ilex tp., Betula, Castanea, Carpinus, Fraxinus o Corylus.

Los datos permiten considerar la existencia de un paisaje fuertemente deforestado, que podría interpretarse como una estepa, dentro de la cual y aprovechando situaciones topográficamente favorables se desarrollarían formaciones arbóreas dominadas por los elementos caducifolios.

La parte del espectro relativa a la vegetación desarrollada sobre el propio depósito muestra la predominancia de los elementos propios de ambientes lacunares, siendo los principales táxones presentes Isoetes, Cyperaceae, Ranunculus, o Sphagmum (Fig. 6).

\section{INTERPRETACIÓN DE LA SECUENCIA}

\subsection{Interestadial Würmiense (OIS 3)}

En las reconstrucciones paleoclimáticas elaboradas a partir de sondeos marinos, el estadial del Würm queda dividido por una compleja fase, el estadío isotópico 3 , que coincidiria con pequeños avances y retrocesos glaciares, aunque en ningún caso llegarían a ser tan importantes como los registrados respectivamente durante los estadiales del Würm o los interestadiales del Prewürm (RUDdiman \& MCINTYRE, 1976; RUDDIMAN ET AL., 1989; COHMAP, 1988; etc.). De este modo, en las reconstrucciones climáticas realizadas para el hemisferio Norte (Frenzel, et al., 1992), se reconoce, durante este periodo, un incremento tanto de las temperaturas medias como de la precipitación, al menos en el SW de Europa, frente a las fases estadiales del Würm; valores que sin embargo, son inferiores a los establecidos para el Interglaciar Eemiense o los registrados durante el Holoceno.

En la actualidad se dispone para el NW Ibérico, de un único registro continuo que abarca la totalidad de los episodios climáticos del Wurm, obtenido en el depósito de Area Longa (Lugo) y cuya antigüedad se remonta al Prewürm (RAmil-Rego \& GómEZORELlanA, 1996; Ramil-Rego et al, 1996A; GómEZOrELlANA, 1997). En la secuencia obtenida, se reconocen durante el estadío isotópico 3 , al menos tres fases de expansión de los elementos arbóreos caducifolios enmarcadas por momentos de predominio de la vegetación arbustiva. El espectro de mayor antigüedad obtenido en el depósito de Caamaño (Fig. 8), muestra un momento de retroceso de la vegetación arbórea, datado entre 36.000 y $30.000 \mathrm{BP}$, pese a lo cual están presentes una gran diversidad de táxones arbóreos entre los cuales predominan los caducifolios (Fig. 8).

La presencia, en el depósito de San Pedro de Maceda, de macro-restos de un bosque de Pinus, permite así mismo afirmar la presencia en Ios territorios litorales Cántabro-Atlánticos de la Península Ibérica de formaciones arbóreas. Estas formaciones presentarían una gradación en cuanto a su fisonomía, de tal forma que en los territorios Cantábricos y los más Norteños de la costa Atlántica se establecería el predominio de los elementos caducifolios mesófilos, mientras en el área Norte de Portugal el dominio cabría atribuirlo a formaciones de Pinus y Juniperus.

\subsection{Estadial Würmiense Final (OIS 2)}

En base a las secuencias oceánicas elaboradas para el Atlántico Norte, se establecen para los 10.000 años que dura el estadío isotópico $2(25.000-15.000 \mathrm{BP})$ 
unas condiciones climáticas de intenso frio, registrándose un importante avance latitudinal de las masas de hielo, cuyo máximo se establece en torno al 18.000 BP (RUDIMAN \& MCINTYRE, 1981; MiX \& RUdIMAN, 1985; CoHmap, 1988; etc.). Según Frencel et al. (FRENCEL ET AL., 1992), durante este periodo se produce un acusado descenso a nivel global de las temperaturas y las precipitaciones, con respecto a los valores actuales e incluso frente al Estadio Isotópico 3.

Los datos paleobotánicos disponibles para este periodo en el SW de Europa, indicarían la hegemonía en el paisaje de la mayor parte del Occidente Europeo, de estepas herbáceas, en las que los elementos crioxéricos tendrian una elevada importancia.

La mayoría de los registros litorales atribuidos al Estadío Isotópico 2, se corresponden con niveles coluviales e incluso periglaciares constituidos por materiales de gran tamaño, escasamente rodados y que en ocasiones superan Ios $10 \mathrm{~m}$ de potencia (Fig. 2). Únicamente de forma excepcional se han podido recuperar registros de naturaleza orgánica, que aparecen frecuentemente truncados por la deposición de materiales inorgánicos. De este modo, la información paleoclimática susceptible de ser empleada en una reconstrucción paleoambiental, se restringe en la actualidad para los territorios litorales Atlánticos del norte peninsular a los espectros obtenidos en los depósitos de Caamaño (RAmil-Rego \& Gómez-Orellana, 1996) y San Pedro de Maceda.

En el diagrama de Caamaño (Fig. 7), se aprecia una clara hegemonía del polen no arbóreo entre el cual domina Poaceae, superando valores del $50 \%$, aunque también están presentes, con valores siempre inferiores al 20, Tubuliflorae y Liguliflorae y un extenso grupo de táxones arbustivos entre los que predomina Ericaceae. Mientras el polen arbóreo no supera el $20 \%$, siendo los táxones mayoritarios Quercus robur tp y Betula (Fig. 7).

El diagrama obtenido en el depósito de Maceda (Fig. 6), presenta una gran similitud, en cuanto al espectro arbóreo, con el obtenido en Caamaño. Las principales diferencias estriban en los porcentajes de

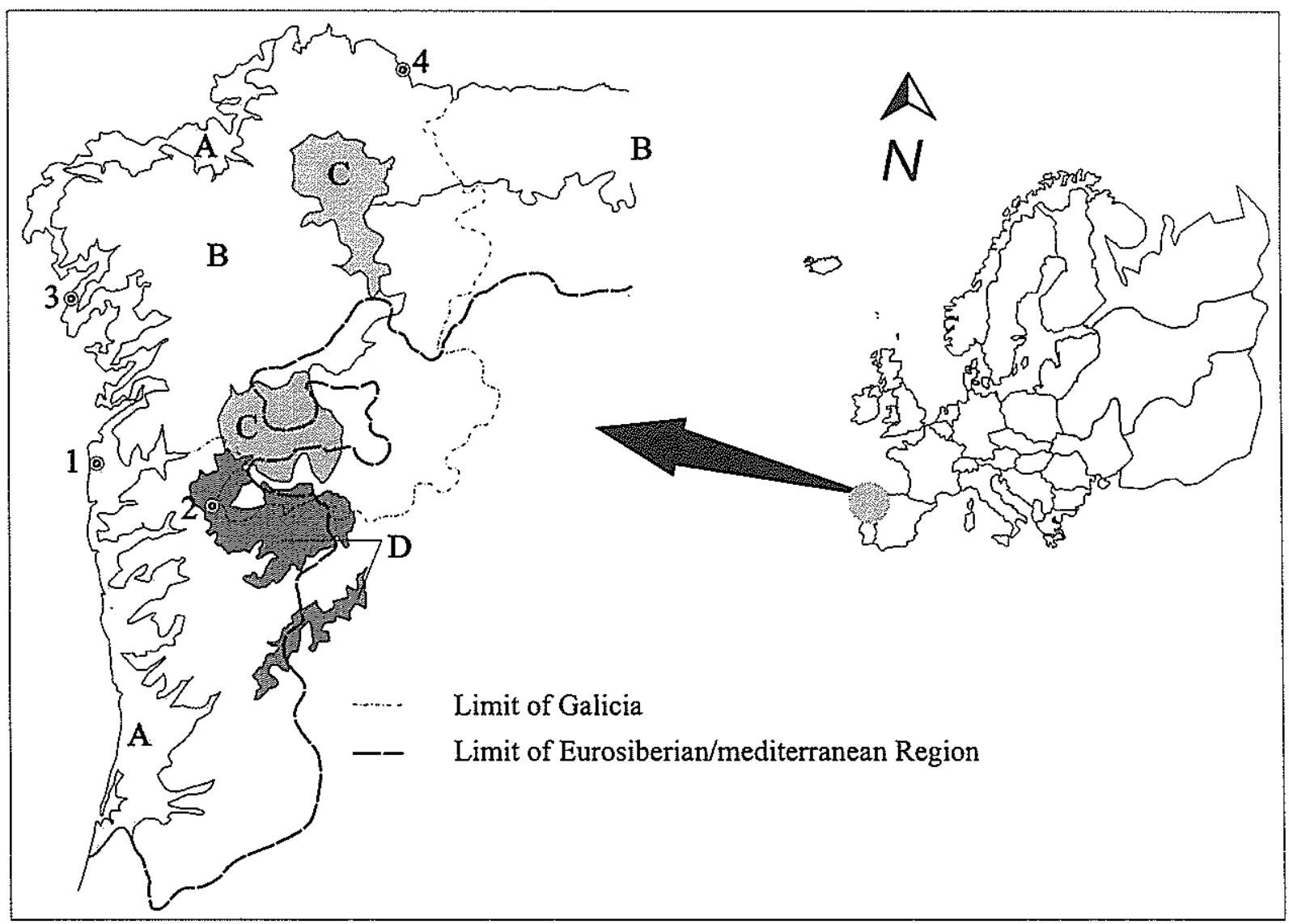

Fig. 3 -Unidades biogeográficas del Nw de la Península Ibérica: A.- Litoral, B.- sublitoral, C.- Depresiones interiores y D.- Montañas interiores Cantábro-Atlánticas (GaliciaMinho). Tomado de Ramil-Rego et AL., 1998. Situación de los depósitos citados en el texto (1. Mougás; 2. Lagoa Marinho; 3. Caamaño; 4. Area Longa).
Fig. 3 - Biogeographycal units in the Northwest Iberian Peninsula: A.- Coastal area, B.- subcoastal area, C.- interior depressions and D.- interior Cantabrian-Atlantic Mountains (Galician-Minho). Redraw from RAMIL-REGO ET AL., 1998. Situación de los depósitos citados en el texto(1. Mougás; 2. Lagoa Marinho; 3. Caamaño; 4. Area Longa). 
los táxones arbustivos, ya que mientras en el depósito de Caamaño la hegemonía corresponde a Ericaceae, en Maceda este taxón no supera valores del $5 \%$, siendo Juniperus el taxón mayoritario.

Valorando los datos disponibles para el Estadial Würmiwense Final en los territorios litorales del NW peninsular, puede establecerse una hegemonía generalizada de las formaciones no arbóreas, en las que Poaceae sería el componente herbáceo dominante, mientras que la representación de elementos crioxéricos como Artemisia, Chenopodium, Thalictrum, Ephedra, etc., se vería reducida frente a territoros más continentales, en respuesta a una mayor humedad ambiental.

La presencia en el paisaje de formaciones boscosas evidenciada durante el Interestadial Würmiensese, perdería importancia en el paisaje, reduciendo su presencia a pequeñas formaciones arbóreas que se desarrollarían aprovechando espacios topográficamente favorables.

La elevada presencia en el paisaje de Juniperus deducida a partir del espectro obtenido en el depósito de Maceda, podría deberse tanto a un incremento de la xericidad con respecto a áreas litorales situadas más hacia el Norte en la costa Atlántica peninsular como a la influencia de la vegetación halófila o mesohalófila (matorrales de Juniperus phoenicea) de carácter local (MATEus, 1992). Este elemento ocupa actualmente terrenos rocosos y arenosos del litoral de la mitad Sur de Portugal, siendo rara su presencia en posiciones más interiores.

En apoyo de esta segunda hipótesis, se muestra el que el paisaje deducido a partir de la secuencia, la presencia de otros elementos crioxéricos es muy baja y similar a la obtenida en otros diagramas (Figs. 6 y 7), reflejando una situación climática de relativamente alta humedad ambiental.
Además el hecho de que los niveles lacustres presentes en este depósito, se encuentren intercalados entre capas de arena identificadas como ambientes de duna (Granja \& Carvalho 1993; DE Groot \& GRANJA, 1998, etc.), hace suponer que el depósito se emplazase bajo la influencia directa de los sistemas dunares, permitiéndose la sedimentación limnética, durante los momentos de menor desarrollo de estos.

Este factor explicaría además, la menor representatividad de las formaciones arbóreas zonales en el espectro de Maceda, frente al depósito de Caamaño (Fig. 7), dado que la mayor influencia de los vientos oceánicos, provocaría la suprarrepresentación de las formaciones azonales de carácter halófilo (MATEUS, 1992; RAMIL-REgo ET AL, 1996).

\subsection{Tardiglaciar}

Los modelos globales y la mayoría de las secuencias regionales del SW de Europa diferencian durante el Tardiglaciar únicamente dos fases frías (Dryas reciente y Dryas antiguo), entre las que se siłúa un periodo atemperado, denominado Interestadio Tardiglaciar.

La disponibilidad de secuencias polínicas en la Península Ibérica para este periodo se incrementa sobremanera frente a las diferentes fases del Wurm. En este sentido, recientemente se ha realizado una propuesta para la caracterización de este periodo en las diferentes unidades biogeográficas que conforman los territorios del NW de la Península Ibérica (GómEZOREllana ET Al., 1997; Ramil-Rego, et al., 1998). En base a las principales secuencias establecidas para cada uno de estos territorios se ha elaborado un modelo de dinámica de la vegetación en el que se establecen las principales diferencias y similitudes para este periodo, cuyas principales características, se muestran en la Tabla 6 y Fig. 3.

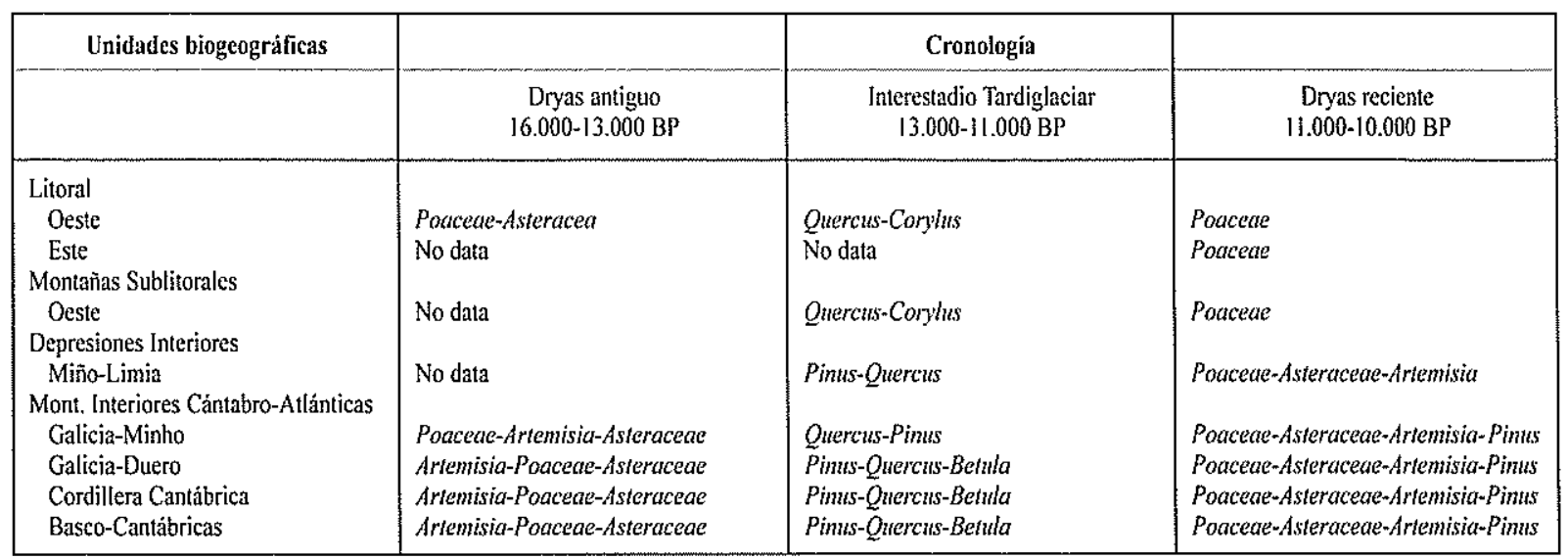

Tabla 6-Principales asociaciones polínicas en los diferentes sectores de la provincia Cantábro-Atlántica durante el Tardiglaciar. Tomado de RAMIL-REGO ET AL., 1998.
Table 6-Main pollen assemblages in the different sectors of the Cantabrian-Atlantic province during the Late-glacial. From RAMIL-REgo et AL., 1998 


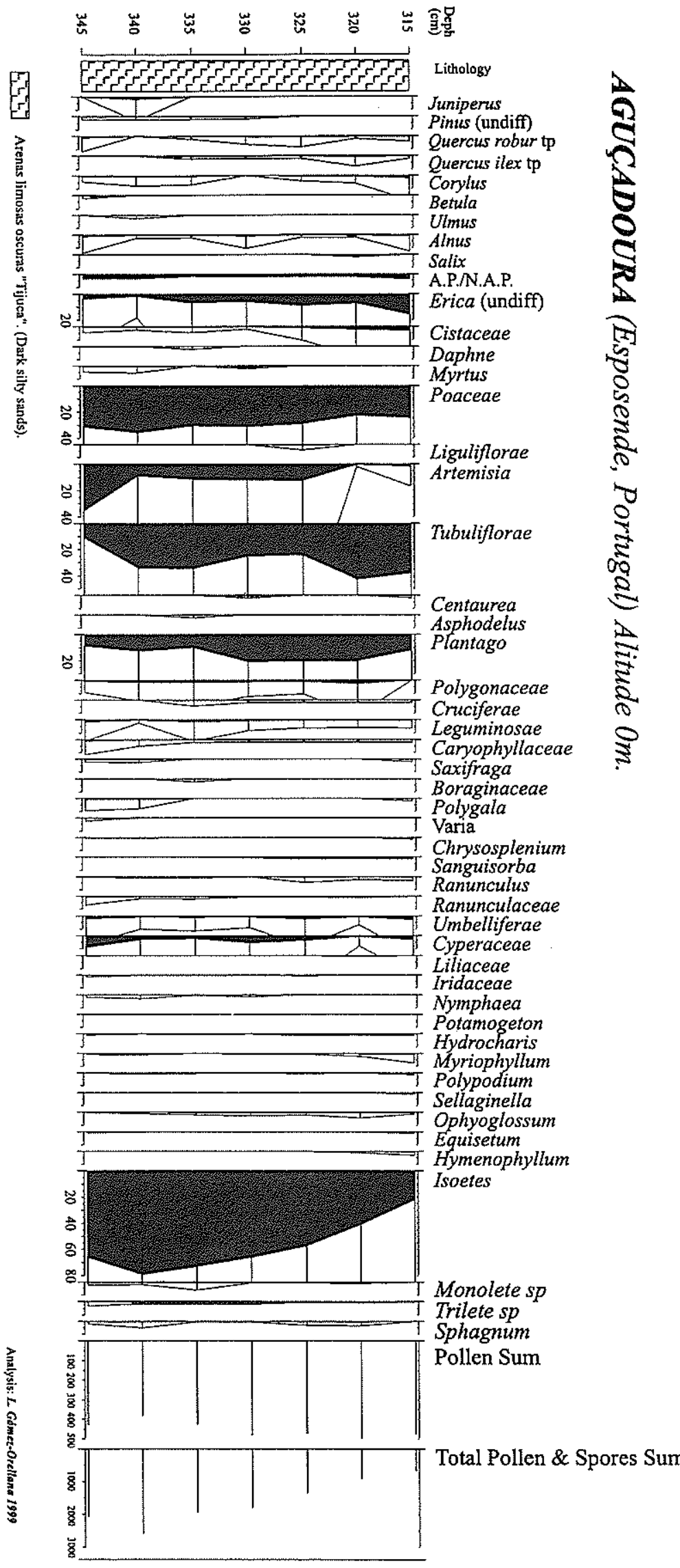

Fig. 4 - Formación de «tijuca» Aguçadoura. Diagrama de porcentajes Fig. 4-Aguçadoura «Tijuca» Formation. Percentage pollen diagram.
Para los territorios litorales Atlánticos de la Península Ibérica, únicamente se dispone para este periodo de la secuencia establecida en el depósito de Mougás (GómEZ-OrELlaNA et al., 1998), mientras que para áreas próximas (Serra do Xerês) la secuencia se ha establecido en base al espectro obtenido en la Lagoa de Marinho (RAMIL-REgo, ET AL., 1996B; RAMLLREGO, et al., 1998).

\subsection{Holoceno}

Con la retirada del frente polar hacia Groenlandia hace aproximadamente 10.000 años, se inicia el actual interglaciar, el Holoceno. Siguiendo criterios paleoclimáticos (RAMIL-REGo et al., 1996A; MUÑoz-SOBRINO ET AL., 1996, etc.) se establecen durante el mismo tres grandes fases: una inicial o anatérmica de en la que se produce un progresivo calentamiento de las masas de agua tanto oceánicas como continentales y que se corresponde en las secuencias con sucesivas fases de expansión de la vegetación arbórea y el comienzo del dominio regional de los bosques. El óptimo climático del Holoceno se corresponde con el momento de mayor termicidad en el SW de Europa y que en los territorios continentales por un incremento de la xericidad.

Por último, la fase catatérmica (3.000BP) se caracteriza por una sucesión de subfases frías y cálidas que desembocarian hacia las condiciones climáticas actuales; el inicio de esta última fase se asocia con aumento de la antropización del territorio, que provocara en la mayor parte de los territorios una merma de las formaciones boscosas.

La estabilidad climática registrada durante el Holoceno ha permitido la preservación de una gran cantidad de secuencias polínicas, siendo por tanto unos de los periodos para los que se dispone de mayor cantidad de datos. De este modo en el NW de la Península, se dispone de un elevado número de registros orgánicos que abarcan la totalidad del Holoceno, la gran mayoría emplazados en áreas interiores. Las secuencias obtenidas en estos territorios ha permitido el establecimiento de las condiciones climáticas generales y los principales cambios en la configuración del paisaje durante el Holoceno (Tabla 7). 


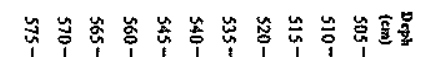

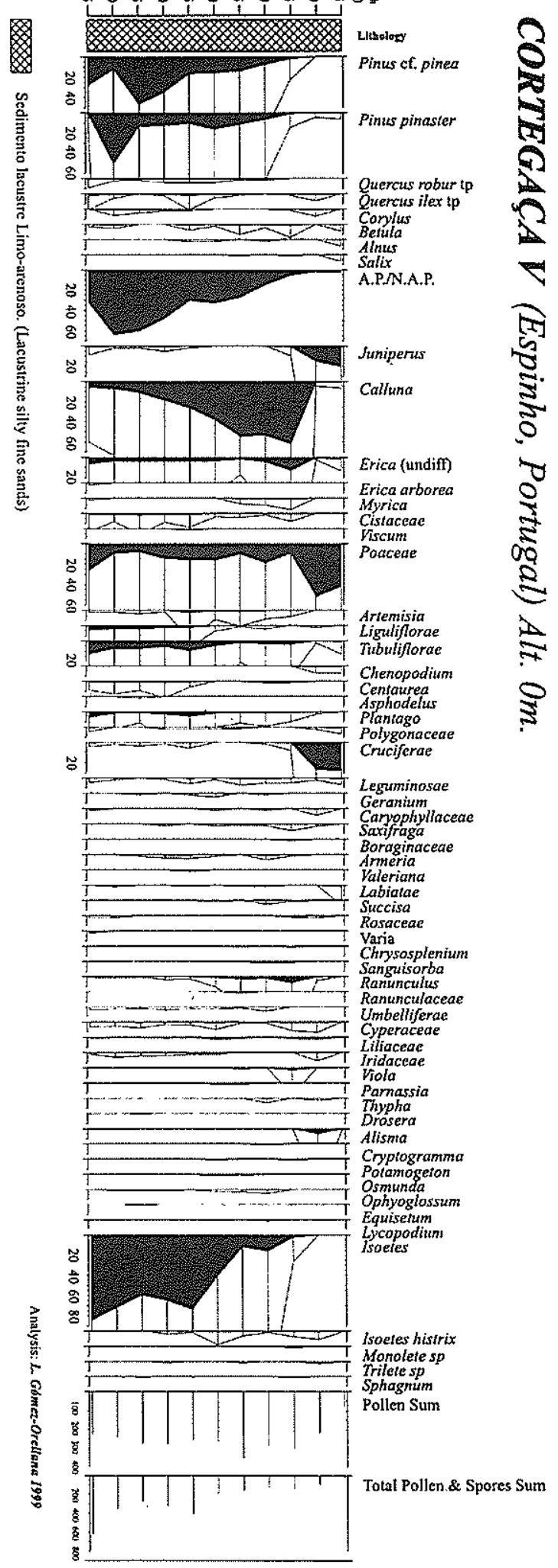

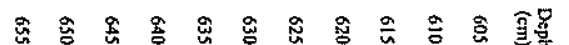

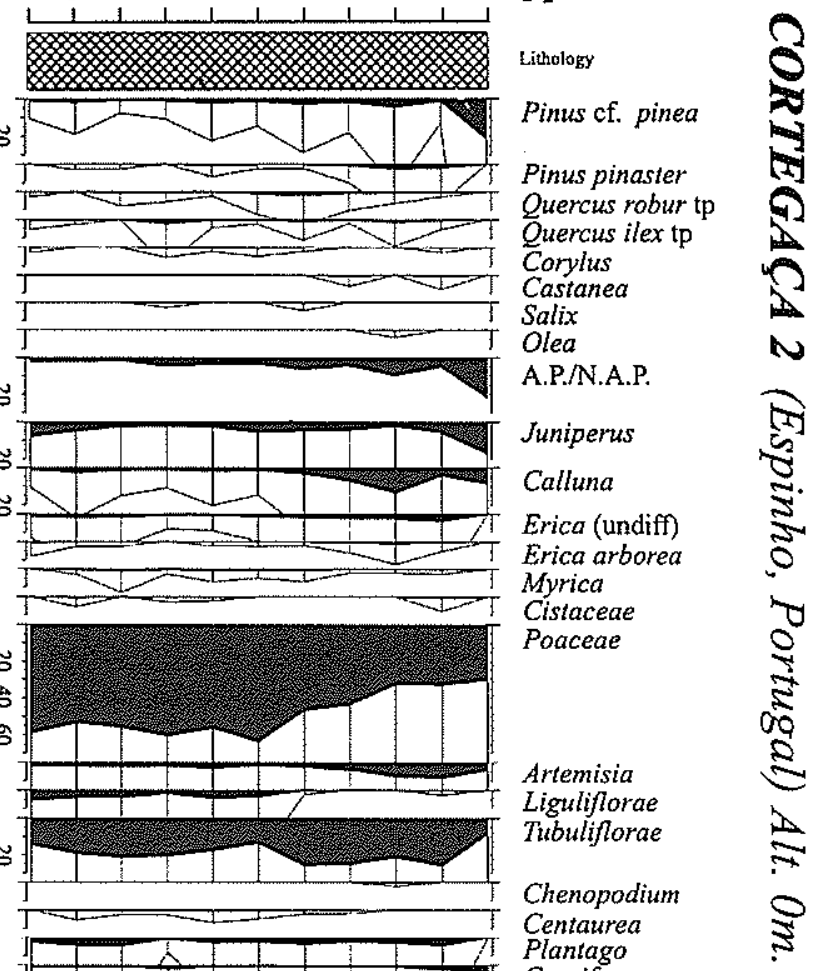

Fig. 5-Formación de la playa de Cortegaça. Diagrama de porcentajes.

Fig. 5-Cortegaça beach Formation. Percentage pollen diagram. 
Mientras en el área litoral, las intensas modificaciones de carácter morfológico ocurridas durante este periodo han condicionado, tanto la disponibilidad de datos como su adecuación para la reconstrucción de los cambios globales del paisaje, dado que las particulares condiciones de los depósitos influyen directamente en el contenido polínico registrado, pudiendo finalmente originar espejismos en cuanto a la vegetación regional se refiere.

$\mathrm{La}$ inestabilidad ambiental que caracteriza en todo el NW Ibérico la fase catatérmica del Holoceno, provocara que la gran mayoría de los depósitos limnéticos litorales cesen su actividad, siendo sepultados y fosilizados por niveles coluviales, dunares e incluso de playa. A su vez, se formaran nuevos depósitos cuyo registro abarca únicamente el último tercio del Holoceno. Dentro de este grupo de depósitos litorales, se pueden diferenciar los ecosistemas fluviomarinos y los humedales no halófilos; como en el caso del nivel descrito en el depósito de Aguçadoura.

Tanto en los depósitos de marisma, como en los humedales no halófilos próximos a la línea de costa, la acción de barrido de los vientos oceánicos conduce en la mayoría de los casos a una suprarrepresentación de las formaciones azonales de carácter halófilo. De esta forma, la valoración de los espectros polínicos obtenidos en estos depósitos, exigen una minuciosa valoración de los aportes polínicos regionales y locales, que evite incurrir en interpretaciones erróneas que han conducido en ocasiones a la desfiguración de los acontecimientos paleoclimáticos acaecidos durante el último tercio del Holoceno. (MATEUS, 1992; RAMILREGO \& GÓMEZ-ORELLANA, 1996).

La información paleobotánica disponible en el litoral Atlántico Eurosiberiano de la Península Ibérica, en relación con las fases de expansión del Holoceno se reduce a los niveles limnéticos de Mougás (GómEZORELLANA et al., 1997), en cuya secuencia se observa un ligero aumento del porcentaje arbóreo, pese a mantenerse el dominio de la representación herbácea (Tabla 7).
Los espectros polínicos procedentes del área litoral del NW Ibérico, atribuibles a la fase de dominio arbóreo del Holoceno, son más numerosos; tanto en Mougás como en otros depósitos situados en la proximidad el margen costero, se evidencia una menor representación de las formaciones boscosas zonales, frente a las secuencias obtenidas en áreas interiores (Tabla 7). Esta diferente representación, podría estar causada por la «transgresión Flandriense», a consecuencia de la cual muchos de los depósitos limnéticos todavía activos, existentes en el litoral-sublitoral, quedan ahora emplazados en las proximidades de la línea de costa, transformándose la vegetación de su entorno, a la vez que el barrido de los vientos oceáni$\cos$ modifica la representatividad de la lluvia polínica, causando finalmente una suprarrepresentación de la vegetación local en los espectros polínicos (MATEUs, 1992; RAMIL-Rego \& GómEZ-ORELLANA, 1996). En la secuencia obtenida en la formación de Cortegaça se observa una muy baja representación de la vegetación arbórea, salvo en la parte inferior del nivel Cortegaça $\mathrm{V}$, en la que Pinus Pinaster y Pinus cf. pinea alcanzan porcentajes cercanos al $40 \%$, cuyo origen podría considerarse local dado la tendencia de estos taxones a instalarse en las cercanías o incluso sobre los propios sistemas dunares. Frente a esta situación, la representación de los táxones planocaducifólios que dominarían el paisaje del NW de la Península lbérica durante el Holoceno medio (Tabla 7) es inferior a la registrada en otros depósitos del área litoral.

Ambos aspectos reflejan una mayor cercanía a la línea de costa o una mayor importancia en el área de los vientos oceánicos, en el área con respecto a territorios litorales más norteños, donde los porcentajes de los táxones arbóreos caducifolios durante la fase de dominio alcanzan valores cercanos al $30 \%$.

Las secuencias disponibles para el último tercio del Holoceno, en el área litoral atlántica de la Península Ibérica permiten establecer, tanto en los territorios Eurosiberianos (SANTOS FIDALGO ef al.,

\begin{tabular}{|c|c|c|c|}
\hline \multirow{2}{*}{ Unidades Morfológicas } & & Cronologia & \\
\hline & $\begin{array}{c}\text { Expansión arbórea } \\
10.000-8.500 \mathrm{BP}\end{array}$ & $\begin{array}{c}\text { Dominio arbórco } \\
8.500-3.000 / 2.500 \mathrm{BP}\end{array}$ & $\begin{array}{c}\text { Influencia Antrópica } \\
>3.500 / 2.500 \mathrm{BP}\end{array}$ \\
\hline \multicolumn{4}{|l|}{ Costa } \\
\hline Oeste & Pimus/Quercus robur type / Corylus & Quercus robur type & Ericaceac-Poaceae-(Quercus) \\
\hline \multicolumn{4}{|l|}{ Montañas Sublitorales } \\
\hline Oeste & Pinus/Quercus robur type / Corylus & Quercus robur type - Corylus & \\
\hline \multicolumn{4}{|l|}{ Depresiones Interiores } \\
\hline Min̄o-Limia & Pinus/Quercus robur type & Quercus robur type & Ericaceae-Poaceae-(Quercus $)$ \\
\hline \multicolumn{4}{|l|}{ Mont. Interiores Cántabro-Allánticas } \\
\hline Galicia-Minho & Pinus/Quercus robur type & Quercus robur type $-($ Pinus $)$ & Ericaceae-Poaceae - (Quercus) \\
\hline
\end{tabular}

Tabla 7-Principales asociaciones polinicas en algunos de los sectores de la provincia Cántabro-Atlántica durante el Holoceno. (Tomado de RAMIL-REgo ET AL., 1998).
Table 7-Main polien assemblages in some sectors of the Cantabrian-Atlantic province during the Holocene. (Redraw from RAML-REGO ET AL., 1998). 


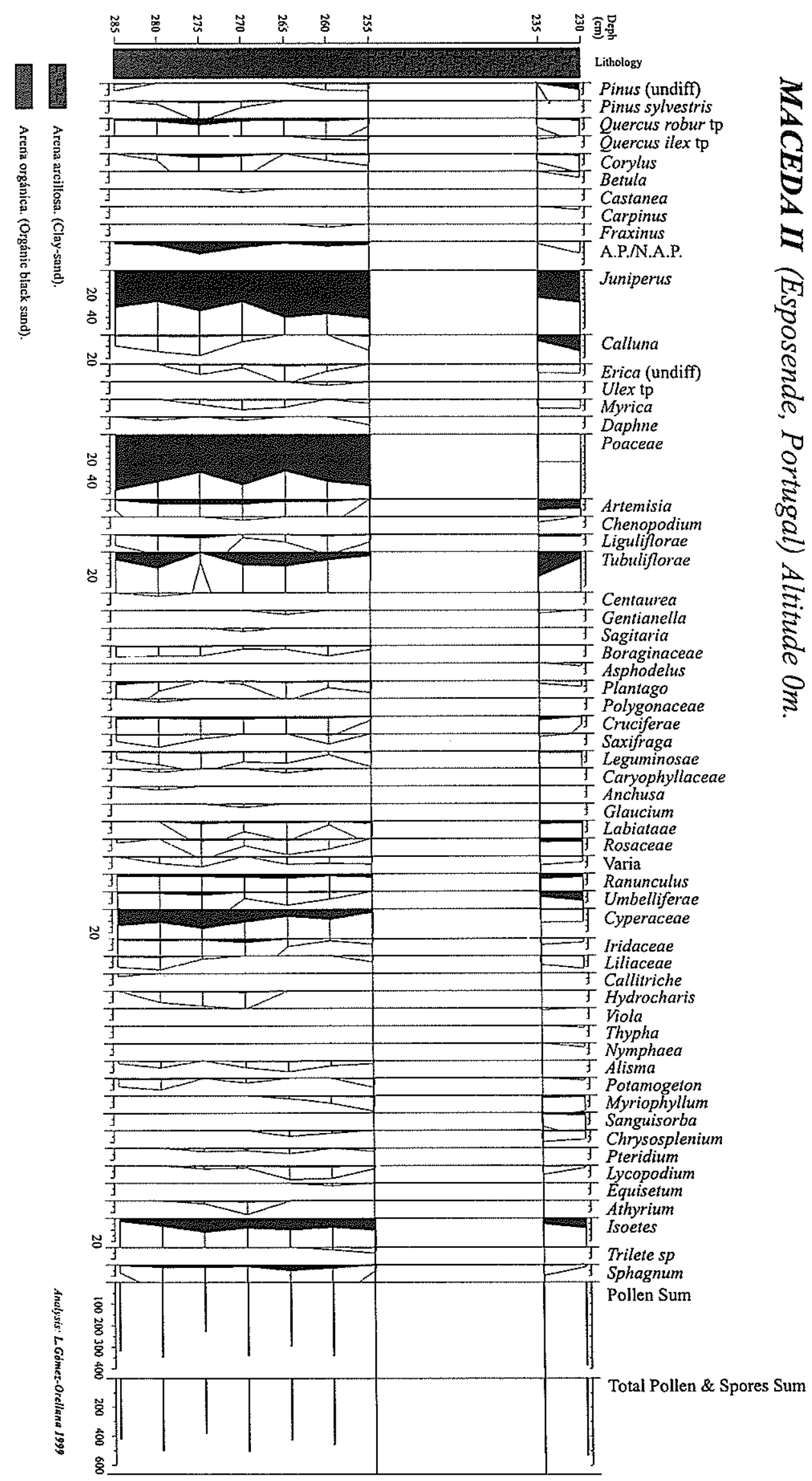

Fig. 6-Formación de la playa de Maceda. Diagrama de porcentajes.

Fig. 6-Maceda beach Formation. Percentage pollen diagram. 


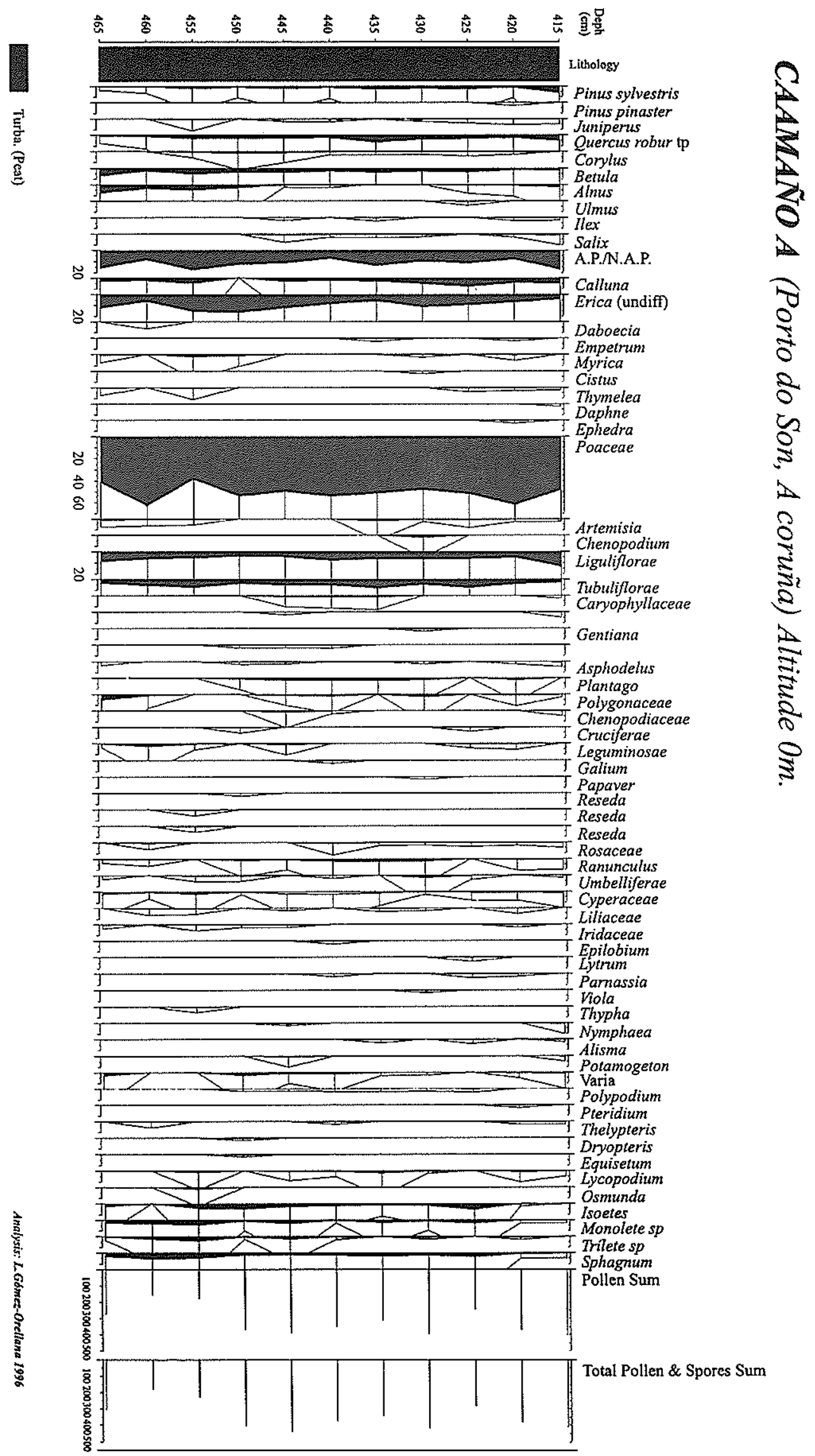

Fig. 7 - Camaño A. Diagrama de porcentajes (A partir de Ramil-Rego \& Gómez-Orellana, 1996).

Fig. 7-Camaño A. Percentage pollen diagram (Redraw from Ramil-Rego \& Gómez-Orellana, 1996). 


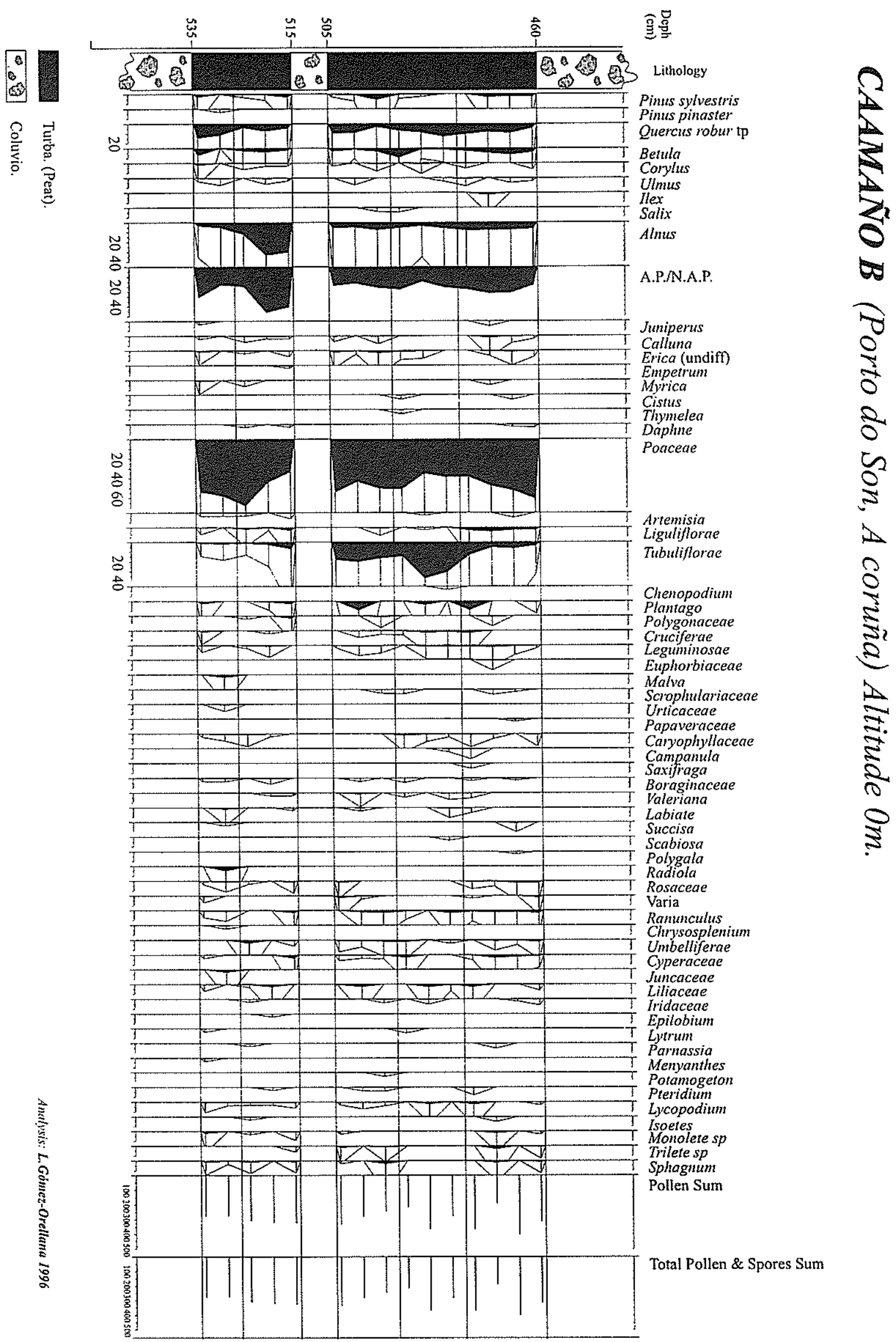

Fig. 8-Camaño B. Diagrama de porcentajes (A partir de Ramil-Rego \& Gómez-Orellana, 1996).

Fig. 8 - Camaño B. Percentage pollen diagram (Redraw from Ramil-Rego \& Gómez-Orellana. 1996). 
1993; RAMIL-REgo \& GómEz-OrELlanA, 1996; GÓMEZ-ORE-LLANA, 1997) como en los mediterráneos (Mateus, 1992, etc.), una dinámica de la vegetación similar a la observada para las áreas más interiores, marcada por los procesos de deforestación y posteriores reforestaciones originadas por la acción humana sobre el paisaje (Tabla 7).

En consonancia con estos datos el diagrama obtenido en el depósito de Aguçadoura, refleja un paisaje fuertemente deforestado consecuencia tanto de la intensa actividad antrópica, como de su cercania a la línea de costa.

El desarrollo del ecosistema limnético, al igual que en los casos anteriores, permanece íntimamente relacionado, con el desarrollo de las oscilaciones eustáticas y/o epirogénicas.

\section{Conclusiones}

Los datos paleobotánicos disponibles, permiten establecer la dinámica de la vegetación en los territorios litorales Cántabro-Atlánticos de la Península Ibérica durante los últimos 36.000 años. Durante este periodo se constata la presencia continuada de formaciones arbóreas cuya importancia en el paisaje varia en función de los cambios climáticos globales mientras que su composición florística presentaría una variación latitudinal.

Las datos de mayor antigüedad se corresponden a un paleobosque de Pinus, desarrollado en el ámbito del Interestadial Würmiense, periodo durante el cual se constata la expansión de las formaciones arbóreas dominadas hacia el Norte por elementos caducifolios de carácter zonal, mientras que hacia el sur se incrementa la importancia de Pinus.

Durante el Estadial Würmiense Final (estadío isotópico 2), periodo en el cual se establecerian a nivel global unas condiciones climáticas de frío extremo, los datos obtenidos se muestran en coherencia con la secuencia polínica obtenida para este mismo periodo en otras áreas litorales del NW Ibérico. Según esta secuencia, el paisaje estaría dominado por formaciones herbáceas o incluso arbustivas, quedando la vegetación arbórea restringida a las posiciones topográficamente más protegidas. La presencia en el paisaje de Juniperus, puede interpretarse como el reflejo de la vegetación halófila o mesohalófila de carácter local, que se estaría desarrollando en los ambientes costeros.

Los diagramas correspondientes al Holoceno, obtenidos en los depósitos de Cortegaça y Aguçadoura (Fig. 4 y 5), muestran una representación arbórea acorde o incluso menor con la obtenida en otros territorios litorales para los periodos que abarcan $(<5.000$ BP). Durante este periodo dos hechos marcan el desarrollo de la vegetación en los territorios litorales, el ascenso eustático Flandriense y el incremento progresivo de la presión antrópica sobre el medio. Ambos factores causan respectivamente una infrarrepresentación de las formaciones boscosas regionales en los espectros polínicos y una intensa deforestación que se ve reflejada en los diagramas, como un pronunciado descenso de los porcentajes arbóreos.

En lo que respecta a la información relativa a la vegetación estrictamente local, que se desarrolla sobre el propio depósito, los datos muestran en todos los casos la existencia de ecosistemas hídricos de carácter continental. Los diagramas que abarcan las últimas fases del Holoceno (Cortegaça II, V y Aguçadoura) reflejan el dominio de Isoetes y la presencia de una gran variabilidad de táxones acuáticos (Fig. 4 y 5), que llega a alcanzar valores del $80 \%$; estas características indicarían la presencia de una importante y permanente capa de agua dulce, que caracterizaría un medio lacunar dominado por las aguas dulces, en coexistencia con los medios semiterrestres. Estos datos confirman la existencia durante este periodo de un complejo sistema de lagunas y medios turbosos o semiturbosos a lo largo del litoral Norte de Portugal.

Los datos obtenidos para el depósito de Maceda (Fig. 6), indican la existencia de un complejo hídrico en el que se desarrollarian tanto lagunas de mayor o menor amplitud con medios turbosos.

A partir de estos datos, puede deducirse que durante extensos periodos de tiempo, en los territorios litorales del Norte de Portugal se desarrollaron, una serie de ecosistemas limnéticos cuya estabilidad estaría intensamente influida por las oscilaciones eustáticas, que finalmente regirian el que se produjese sedimentación limnética o que estos ecosistemas quedasen sepultados por el avance de los frentes dunares.

\section{AgRadecimientos}

Al Dr. G. Soares de Carvalho, Profesor jubilado de la Univerisidade do Minho y a la Dr. H. Granja Profesora de la Universidade do Minho, por su inestimable colaboración en la localización de los depósitos, así como en la interpretación cronológica y estratigráfica de los niveles muestreados. A Castor Muñoz-Sobrino y Manuel A. Rodríguez-Guitián por su colaboración en la recogida de muestras. Los resúmenes han sido traducidos por Patricia Bautista (Portugués) y Pedro Fernández (Inglés).

Este trabajo se incluye dentro del proyecto FEDER UE-CICYT (1FD97-1481-C02). 


\section{Bibliografía}

AirA, M.J. \& Ramil-Rego, P. (1995) - «Datos paleobotánicos del Norte de Portugal (Baixo Minho)", Lagascalia, 18(1), p.23-38.

ANDRADE, M.M. (1944) - «Estudo polínico de algumas formaçoes turfo-lignosas portuguesas», Publ. Mus. Lab. Min. Geol. Fac. Cièn., XXXVII, $2^{\mathrm{a}}$ série, p.5-1I.

ANDRADE, M.M. (1945) - «Contribuiçâo da análise polínica para o conhecimento do género Pinus no Pliocénico Superior Portugês», Bol. Soc. Geol. Pornugal, IV, p.1-6.

BroscuE, K.U. (1982) - «Studien zu Jngpleistozänen und Holozäne sedimenten undfossilen böden im küstengebiet von WestGalizien (NW-Spanien)», Eiszeitalter u. Gegenwart, 32, p. $63-80$.

BRosCHE, K.U. (1983) - «Die geomorphologish - bodengeographische Deutung der pleistozänen Sedimente und der fossilen Böden an der Playa de Barañan (westl. La Coruña) und bei , Cangas de Foz (Nord-Galicien)", Eiszeiralter u. Gegenwart, 33, p. 95-117.

Butzer, K.W. (1967) - «Geomorfology and stratigraphy of the Paleolithic site of Budiño (Prov. de Pontevedra, Spain)», Eiszeitaller und Gegenwart, 18, p. 82-203.

Cano, J.; Fumanal, M.p. ; Ferrer, C.; Usera, J.; Blazquez, A.M. \& OLmo, J. (1997) - «Evolución de la costa meridional de Galicia durante el Cuaternario Superior», in J.R. VIDAL. (Ed.), Cuaternario lberico, Huelva, p. 33-46.

Carvalho, G. \& Granja, H.M. (1991)- «Processos geológicos durante o Plistocénico e o Holcénico na zona costeira do Noroeste de Portugaly, Memórias e Noticias do Museo e Laboratório Mineralógico e Geológico, Univ. Coimbra, 112, p. 58-66.

Colmap Memblers. (1988) - "Climatic changes of the last 18.000 years: Observations and model simulations», Science, 26 (241), p. 1043-1052

De: Groot; T. \& Granja, H.M. (1998)- «Coastal environments, sea-level and neotectonism from cored boreholes (Northwest Portugal)y, Journal of Coastal Research, 26, p. 115-124.

Ei.flA, E. (1964)-«Analyse pollinique de sédiments PosiGlaciaires de L'Embouchure du Leça, près de Porton, Boletin do Museu e Laboratógico e Geológico da Facultade de Ciencias, Lisboa, 10 (1), p. 45-52.

FriNzEL, B. (1968) - «The Pleistocene Vegetation of Northern Eurasia», Science, 161(3842), p. 637-649.

FRENZEL, B. (1989) - «The history of the flora and vegetation during the Quaternary", Progress in Botany, 50, p. 327-340.

FrEENZEL, B.; PÉCSI, M. \& VELICHKO, A.A. (Eds) (1992) - Allas of paleoclimates and paleoemviroments of the Northern Hemisphere. Late Pleistocene-Holocene, Gustav Fisher Verlag, Budapest-Stuttgard, 153p.

GÓMEZ-ORILLAANA, L. (1997) - Caracterización de la vegetación y dinámica climática durante el Wurm en los sectores litorales de Galicia, Memoria de Licenciatura, Facultade de Bioloxía, Universidade de Santiago de Compostela, 118p.

Gómez-Orzllana, L.; RAMle-Rego, P \& Muñoz Sobrino, C. (1998) - «Una nueva secuencia polínica y cronológica para el depósito pleistoceno de Mougás (NW de la Península Ibérica», Revue de Paleobiologie, 17(1), p. 35-47.

GRANJA, H.M. (1991) - «Os sistemas dunares a norte da laguna de Aveiro e a neotectónica recente», Conferencias e Communicações do Seminário Zona Costeira e Problemas Ambientais, Universidade de Aveiro, p. 53-64.

Granja, H.M. \& DE Groot, T.(1996) - «Sea level rise and neotectonismin a Holocene coastal environment at Cortegaça beach (NW Portugal): A case Study', Journal of Coastal Research, 12(1), p. 160-170.

GranIA, H.M. \& SoARes de CaRvalho, G. (1993) - «A synthesis of the researches about the Pleistocene-Holocene evolution of the NW coastal zone of Portugalm, Proceedings of The First Internacional Conference on the Mediterranean Coastal Enviroment, MEDCOAST, Turkey, p. 160-165.
Granja, H.M. \& SOARES De CARVALHO, G. (1994) - «How can the Holocene help to understand coastal zone evolutión?», Proceedings of the Second International Symposium EUROCOAST, Littoral 94, Lisboa, 1, p. 149-167.

Granja, H.M.; Gomes, p. \& Soares De Carvalho, G. (1995) «Morfologia e Cronologia dos sistemas dunares da zona costeira Nordeste de Portugal», Memorias do Museo e Laboratório Mineralógico e Geológico, Univ. Porto, 4, p. 417-420.

MARY, G. (1983) - «Evolución del margen costero de la Cordillera Cantábrica en Asturias desde el Mioceno", Trabajos de Geología de la Univ de Oviedo, 13, p. 3-55.

Mary, G.; Medus, J. \& DelizRias, G. (1977) - «Documents sur l'évolution de la flore du Littoral Nord Espagnol au Wiirmm, Recherches Francaisses sur le Quaternaire. INQUA 1977. Supplement au Bulletin AFEQ, 1(50), p. 23-31.

MATEUS, J.E. (1992). Holocene and present-day ecosystems of the Carvalhal Region, Southwest Portugal, Tesis doctoral., Rijksuniversiteit te Utrecht, $184 \mathrm{p}$.

MATEuS, J.E. \& Quesro\%, p. F. (1993) - «Os estudos de vegetaço Quaternária em Portugal; contextos, balanço de resultados, perspectivas», in G. Somriss di CARVAl.HO; A. BURn Ferreira \& J.C. Sinna Martinez (Coord.), O Quaternário em Portugal. Balanco e Perspectivas, Lisboa, p. 105-131.

MEIRILLES, J. \& TIEXIER, J.p. (1993) - «O Quaternário do Litoral do Minho. Uma sintese lito e cronoestratigráfica», Actas da 3. "Reunião do Quaternàrio Iberrico, Coimbra, p. 395-408.

Muñoz Solikino, C.; RAMIL-REgo, p. ; Gómez-ORELLLANA, L. \& Roprigunz GumTik, M. (1996) - «Modificaciones del paisaje vegetal durante el cuaternario en el NW de la Peninsula lbérica, contextualización con las secuencias del SW de Europa», Fervedes, 2, p. 117-150.

MIX, A.C. \& RUDDIMAN, W.F. (1985) - «Structure and timing of the last deglaciation: oxigen-isotope evidence», Quaternary Science Reviews, 4, p. 59-108.

MoORt, p. D.; WIBB3, J.A. \& COLLINSON, M.E. (1991) - Pollen anilisis, Blackwell Scientific Publications, Oxford. 216p.

Nons, H. (1966) - Les regions cotiéres de la Galicie (Espagne). Ende géomorphologique. Publications de la Faculté des Lettres de l'Université de Strasbourg. Foundation Baulig, 591p.

PÉRI:z OBıol, R. \& JuLlA, R. (1994) - «Climatic Change on the Iberian Peninsula Recorded in a 30,000-Yr Pollen Record from Lake Banyoles", Quaternary Research, 41, p. 91-98.

Pons, A. \& RELLLE, M. (1988)-«The Holocene- and Upper Pleistocene pollen record from Padul (Granada, Spain): a new estudy", Palaeogeography, Palaeoclimatology. Palaeoecology, 66 , p. 243-263.

QUE⿰ROZ, p. F. (1985) - «Dados para a História da Vegetação Holocénica da Região da Lagoa de Albufeira (Sumário das conclusões do estudio paleoecológico da Estacada». Actas da $I^{a}$ Reuniäo do Quatemario lbérico, II, Lisboa, p. 251-259.

QUelRoz, p. F. (1989) - «A peliminary paleoecological study at Estacada (Lagoa de Albufeira) ", Revista de Biologia, 14, p. $3-16$.

RAMIL-REGO, p. (1992) - La vegetación cuaternaria de las Sierras Septentrionales de Lugo a través del análisis polinico, Tesis Doctoral, Facultad de Biologia, Universidad de Santiago de Compostela. 356p.

RAMIL-REgo, p. \& GÓmez-Orellana, L. (1996) - «Dinámica climática y biogeográfica del área litoral-sublitoral de Galicia», in p. RAMIL Rego; C. FERnÁNDEZ RodRiguez \& M. RodRigulzZ GUITIÁN (Coord.), Biogeografia Pleistocena-Holocena de la Peninsula Ibérica, Xunta de Galicia, p. 43-71.

Rami-Rego, p. ; Gómez-Orellana, L.; Muñoz Sobrino, C. \& Rodriguez GuitiÁN, M. (1996A) - «Valoración de las secuencias polínicas del noroccidente Ibérico para el último ciclo glaciar-interglaciar", Férvedes, 3, p. 33-116.

Ramil-Rego, p.; TABonda Castro, M.T.; Diaz-Fierros, F. \& Aira RodríguEz, $\mathrm{M}^{2} . J$. (1996B) - «Modificación de la cubierta vegetal y acción antropica en la Región del Minho (Norte de Portugal) durante el Holocenon, in p. RAMIL-REGo, C. Fernández Rodriguez \& M. Rodriguez Gumitán (Coord.), 
Biogeografia Pleistocena de la Peninsula lbérica, Xunta de Galicia, p. 199-214.

Ramil-Rego, p. ; Muñoz-Sobrino, C.; Rodriguez-GurtiÁn, M. \& GOMEZ-ORELLANA, L. (1998) - «Differences in the vegetation of the North Iberian Peninsula during the last 16.000 years», Plant Ecology, 138, p. 41-62.

RUDDIMAN, W.F. \& MCINTYRE:, A. (1976)-«Northeast Atlantic Paleoclimatic changes over the past 600.000 years", Geological Society of America, Memoir 145, p. 11 i-146.

RUDDIMAN, W.F. \& MCINTYRE, A. (1981) - «The north Atlantic Ocean during the last deglaciation', Palaeogeography, Palaeoclimatology, Palaeoecology, 35, p. 145-214.

Ruddiman, W.F., Raymo, M.E., Martinson, D. G., Clement, B. M \& MCINTYRE, A. (1989) - «Pleistocene evolution: Northern hemisphere ice sheers and North Atlantic Ocean», Paleogeography, 4(4), p. 353-412.

SAÁ OTERO, M. P. (1985) - Contribución a la cronologia de sedimentos costeros por análisis polínico, Tesis Doctoral. Facultad de Biologia, Universidad de Santiago de Compostela, 338 p.

SiNCHEZ GoNit, M'.F. (1991) - Analyses palynologiques des replissages de grotte de Lezetxiki, Labero et Urtiaga (Pays Basque espagnol). Leur place dans le cadre des sequences polliniques de la côte Cantabrique et des Pyrénées occidentales. de la Taphonomie pollinique à la reconstitution de lénviroment, Thèse, Museum National d'Historie Naturelle, Paris, 290 p.
Santos fidalgo, l.; Bao Casal, R.; Jalut, G. \& Cearreta, A. (1993) - «Estudio micropaleontológico del depósito costero holoceno de Seselle (Ria de Ares, A Coruña, España)", Actas $3^{\circ}$ Reuniâo do Quaternario Ibérico. G.T.E.Q.-A.E.Q.U.A., Coimbra, p. 329-338.

TE:XIER, J. p. \& Meireles, J. (1987) - «As Formações Quaternarias do Litoral do Minho (Portugal): propostas para uma nova abordagem climato-cronológica e dinâmican, Cadernos de Arqueologia, Serie 11, 4, p. 9-33.

Teixier, J. p. ; Bertran, p. ; Mrireles, J. (1989) - «Les dépôts «areno-pelitiques» du littoral Nord du Portugal: Approche micromophológique, implications dynamiques, paleopedológiques et paleoclimatiques", Trabalhos de Antropologia e etnologia, Fascículo 1-4 (29), p. 10-22.

TURNER, C. \& HANNON, E. (1988)- «Vegetational evidence for late Quaternary climatic changes in southwest Europe in relation to the influence or the North Atlantic Oceans. Philosophical Transactions of the Royal Society of London, B 318, p. $451-485$.

Z13YsZEivski, G. (1958) - «Le Quaternaire du Portugal». Boletin da Sociedade Geológica de Portugal, XIII (1-11), p. 2-227

ZbYsZEwSKI, G. \& TEXE:iRA, C. (1949) - «Le niveau quaternaire marin de 5-8 mètre au Portugal». Boletin da Sociedade Geologica de Portugal, 8 (1-2), p. 1-6 